\title{
Wound healing activity of cuttlefish gelatin gels and films enriched by henna (Lawsonia inermis) extract
}

Mourad Jridi ${ }^{* 1}$, Sabrine Sellimi ${ }^{1}$, Khaled Ben Lassoued ${ }^{2}$, Sabrine Beltaief ${ }^{1}$, Nabil Souissi ${ }^{3}$; Leticia Mora ${ }^{4}$, Fidel Toldra ${ }^{4}$, Abdelfatteh Elfeki ${ }^{2}$, Moncef Nasri ${ }^{1}$ and Rim Nasri ${ }^{1}$

1. Laboratoire de Génie Enzymatique et de Microbiologie, Université de Sfax, Ecole Nationale d'Ingénieurs de Sfax, B.P. 1173-3038 Sfax, Tunisia.

2. Animal Ecophysiology, Faculty of Sciences of Sfax, Tunisia

3. Laboratoire de Biodiversité et Biotechnologie Marine. Institut National des Sciences et Technologies de la Mer. Centre de Sfax. BP 1035. 3018 Sfax, Tunisia.

4. Instituto de Agroquímica y Tecnología de Alimentos (CSIC), Avenue Agustín Escardino, 7, 46980 Paterna, Valencia, Spain.

* Corresponding author. Tel.: +216 28142 818; Fax: +216 74275595.

Mourad Jridi: Laboratoire de Génie Enzymatique et de Microbiologie, Université de Sfax, Tunisia.

Ecole Nationale d’Ingénieurs de Sfax, B.P. 1173-3038 Sfax, Tunisia.

E-mail address: jridimourad@gmail.com 


\section{Abstract}

The in vivo wound-healing potential of gels and films based on cuttlefish skin gelatin (CSG) incorporated with aqueous henna extract (AHE) (at 50 and $500 \mu \mathrm{g} / \mathrm{ml}$ ) was studied. Since wound healing is related to reactive oxygen species (ROS), this study was first conducted to evaluate the antioxidant activity of AHE by DPPH radical-scavenging, $\beta$ carotene-linoleate bleaching, and reducing power assays. The major volatile compounds were lawsone, dimethyl sulfoxide, dimethyl sulfide, eugenol and maltol. The finding of the study showed that the incorporation of AHE into gelatin gels and films enhanced the antioxidant activity in a dose-dependent manner. In the wound-healing study, topical application of gelatin hydrogels or films enriched by AHE, on the wound site in a rat model, enhanced significantly wound healing activity and helped to prevent from inflammation damage, when compared to the control and CICAFLORA ${ }^{\circledR}$-treated groups. Further, all preparations were found to improve the antioxidant status of treated rats as was evidenced by increased antioxidant enzymatic activities and reduced MDA content. The increase in the activities of catalase (CAT), superoxide dismutase (SOD) and gluthatione peroxydase (GPx) in wound tissues revealed that bioactive compounds in AHE, film and gel are able to enhance the healing of wounds by reducing the damage caused by ROS. Wound-healing activity was confirmed by histopathology studies. The obtained results showed that the addition of AHE to the gelatin matrix could improve the wound healing activity.

Keywords: Gelatin gel; Gelatin film; Antioxidant activities; Wound-healing activity; Inflammatory markers; Histological examination. 


\section{Introduction}

Medicinal plants are part of human society to combat diseases, from the dawn of civilization. Herbal medicines are in great demand in the developed as well as developing countries for primary healthcare because of their wide biological and medicinal activities, high safety margins and less costs.

Henna (Lawsonia inermis), is one of the most famous plants that was studied in herbal medicine. It belongs to Lythraceae's family and it is best known for its natural orange-red color contained in the leaves. Since more than 9,000 years, this plant has been used cosmetically and medicinally. For instance, traditionally, in Tunisian culture, henna leaf paste or powder has been widely used for hand, hair, nails and feet dyeing. Furthermore, due to its therapeutic efficiency, it is used for alleviating jaundice, skin and venereal diseases, and smallpox. Thus, actually, this blessed plant represents the subject of several scientific studies. Leaves extracts have shown various biological activities such as antidiabetic [1,2], antifungal [3], antiviral [4], antioxidant [5,6] and anti-inflammatory [7] effects and hence they may be a potential material for biomedical industry. The antioxidant and anti-inflammatory activities of L. inermis include the cellular damage repairing effect.

Inflammation is a type of non-specific immune reaction that occurs in response to injury or infection. Wounds, caused by the breaks in the normal tissue continuum, may be created by physical, chemical, thermal, microbial, or immunological, abuse of the tissue [8]. They result in a variety of cellular and molecular sequels. Wound healing is a complex multifactorial process involving inflammation, proliferation, remodeling, which behave in a harmonious way in order to guarantee tissue reparation. The process of wound healing may be hampered by the presence of free radicals, which can damage wound surrounding cells, or by microbial infection [9]. In fact, the wound site is rich in both oxygen and nitrogen centered reactive species along with their derivatives. The presence of these radicals will result in oxidative 
stress leading to lipid peroxidation, DNA breakage, and enzyme inactivation, including free radical scavenger enzymes [10]. Therefore, advanced researches are carrying out to find novel bioactive compounds, with potential antioxidant and tissue repairing abilities [11].

Many biomaterials used in wound healing represent components that naturally exist in the skin and active during the healing process. Due to their intrinsic biological properties and biocompatibility, these materials are advantageous. Gelatin, derived from the collagen, is used as a natural material thanks to its safe properties, such as low-toxicity, biodegradability, biocompatibility and non-immunogenicity [12]. Furthermore, gelatin gels have attracted much attention in tissue engineering and drug delivery applications in recent years $[12,13]$. In order to obtain smooth and compact structure of nano- and microgels, inorganic material such as $\mathrm{CaCO}_{3}$, [12,14] can be added. In addition, gelatin hydrogels [15] and gelatin films [16] have also been investigated successfully for their use as bioactive materials. Several works reported that topical applications of bioactive molecules with antioxidant activities in patients have shown to improve significantly wound healing and protect tissues from oxidative damage [17].

Therefore, in the current study, the incorporation of AHE in CSG-gels and CSG-films was investigated. Hydrogels and films were used as dressings thanks to their biocompatibility and biodegradability. Thereafter, the antioxidant properties of these dressings (films and gels) enriched or not by aqueous extract of henna (L. inermis), were investigated in vitro and in vivo, using skin wound healing rats model.

\section{Materials and Methods}

\subsection{Cuttlefish skin preparation}

Cuttlefish by-products were obtained from marine processing industry "IMPEX" located in Sfax City, Tunisia. The samples were packed in polyethylene bags, placed in ice with a sample/ice ratio of approximately $1: 3(\mathrm{w} / \mathrm{w})$. They were washed twice with tap water to 
eliminate the dark ink, which consists of a suspension of melanin granules in a viscous colorless medium. Finally, cuttlefish outer skin was collected and then stored in sealed plastic bags at $-20{ }^{\circ} \mathrm{C}$ until use for gelatin extraction and further analysis.

\subsection{Gelatin extraction}

Cuttlefish skin gelatin (CSG) was isolated from alkali-pretreated skin of cuttlefish using pepsin as previously reported [16].

\subsection{Plant collection and aqueous henna extract preparation}

Fresh leaves of $L$. inermis were obtained from Gabes City-Tunisia. The plant was identified by a toxonomist in the department of Biological Sciences, University of Science, Sfax-Tunisia. The aqueous henna extract was prepared according to the method of Mittal and Aguwa [18]. The leaves of henna were washed with distilled water. They were sun dried and then grounded into powder using pestle and mortar. Fifty grams of the powdered leaves were mixed with $500 \mathrm{ml}$ of distilled water in a flat bottom flask and stirred for $24 \mathrm{~h}$ at room temperature $\left(25^{\circ} \mathrm{C}\right)$. The mixture was centrifuged at $10,000 \mathrm{~g}$ for $15 \mathrm{~min}$ using a refrigerated centrifuge to remove insoluble material. The supernatant was collected and freeze dried.

\subsection{Analysis of volatile compounds}

Volatiles compounds analysis was performed using solid phase microextraction (SPME) with an $85 \mu$ m Carboxen/ Polydimethylsiloxane (CAR/PDMS) fibre. 0.5 gram of henna plant extract was weighted into a $20 \mathrm{ml}$ head space vial sealed with a PTFE faced silicone septum. The vial was equilibrated at $37{ }^{\circ} \mathrm{C}$ for $30 \mathrm{~min}$ and then, SPME fiber was exposed to the headspace during $3 \mathrm{~h}$ at $37^{\circ} \mathrm{C}$.

The identification of volatile compounds was performed using an Agilent HP 7890 series II gas chromatogram (GC) (Hewlett- Packard, Palo Alto, CA) with an HP 5975C mass selective detector (Hewlett-Packard) equipped with Gerstel MPS2 multipurpose sampler (Gerstel, Germany). The compounds adsorbed by the fiber were desorbed in the injection port 
of the GC-MS for 5 min at $240{ }^{\circ} \mathrm{C}$ with purge valve off (splitless mode). The compounds were separated in a DB-624 capillary column J\&W Scientific (Agilent Technologies, USA) (30 m, $0.25 \mathrm{~mm}$ i.d., film thickness $1.4 \mu \mathrm{m})$. Helium was used as carrier gas with a linear velocity of $34.3 \mathrm{~cm} / \mathrm{s}$. The GC oven temperature program began at $38{ }^{\circ} \mathrm{C}$, held for $5 \mathrm{~min}$, ramped to 100 ${ }^{\circ} \mathrm{C}$ at $8{ }^{\circ} \mathrm{C} / \mathrm{min}$, then to $150{ }^{\circ} \mathrm{C}$ at $2{ }^{\circ} \mathrm{C} / \mathrm{min}$, maintained at $150{ }^{\circ} \mathrm{C}$ for $5 \mathrm{~min}$, then to $210{ }^{\circ} \mathrm{C}$ at 3 ${ }^{\circ} \mathrm{C} / \mathrm{min}$ and finally, held at $210{ }^{\circ} \mathrm{C}$ for $5 \mathrm{~min}$. The total run time was $67.75 \mathrm{~min}$ and GC-mass spectrometer interface was maintained at $240{ }^{\circ} \mathrm{C}$. Mass spectra were obtained by electron impact at $70 \mathrm{eV}$, and data were acquired across the range 29-400 amu (scan mode). The compounds were identified by comparison with mass spectra from the library database (Nist’05), kovats retention index and by comparison with authentic standards.

\subsection{Preparation CSG gels incorporated with AHE}

Gelatin solution was prepared by mixing $4 \mathrm{~g}$ of freeze-dried gelatin in $100 \mathrm{ml}$ of distilled water at $40{ }^{\circ} \mathrm{C}$ for $30 \mathrm{~min}$. Therafter, gelatin solutions were incorporated with 50 $\mu \mathrm{g} / \mathrm{ml}$ and $500 \mu \mathrm{g} / \mathrm{ml}$ of AHE and mixed under constant stirring for $1 \mathrm{~h}$ at $4{ }^{\circ} \mathrm{C}$. G1 and G2 were referred to CSG gels incorporated with 50 and $500 \mu \mathrm{g} / \mathrm{ml}$ of AHE, respectively. Gelatin based gel prepared without AHE, was used as control and referred to G0.

\subsection{Preparation CSG films incorporated with AHE}

Gelatin solution was prepared by mixing $4 \mathrm{~g}$ of freeze-dried gelatin in $100 \mathrm{ml}$ of distilled water in the presence of $15 \%$ glycerol (based on protein) as plasticizer. Then, AHE was added to gelatin solution at 50 and $500 \mu \mathrm{g} / \mathrm{ml}$ and the mixtures were stirred for $30 \mathrm{~min}$ at $40^{\circ} \mathrm{C}$. Gelatin solutions with or without AHE were cast onto a rimmed silicone resin plate (6 $\mathrm{cm} \times 6 \mathrm{~cm})$, air-blown for $12 \mathrm{~h}$ at room temperature $\left(25^{\circ} \mathrm{C}\right)$ and dried for $48 \mathrm{~h}$ at a temperature of $25^{\circ} \mathrm{C}$ and $50 \%$ relative humidity (RH). Dried films were manually peeled off and then subjected to analyses. F1 and F2, were referred to films containing 50 and $500 \mu \mathrm{g} / \mathrm{ml}$ of AHE, respectively. CSG film without AHE was named F0. 


\subsection{In vitro antioxidant activity}

\subsubsection{DPPH free radical-scavenging assay}

The DPPH free radical-scavenging activities of AHE, CSG gelatin films and gels were determined as described by Bersuder et al. [19]. Films were cut into small pieces ( $\mathrm{m}=50 \mathrm{mg}$ ) and suspended in $0.5 \mathrm{ml}$ of distilled water. An aliquot of $500 \mu \mathrm{l}$ from AHE or each dissolved films or gelatin gels was mixed with $500 \mu \mathrm{l}$ of $99.5 \%$ ethanol and $125 \mu \mathrm{l}$ of $0.02 \% \mathrm{DPPH}$ in 99.5\% ethanol as free radical source. The mixtures were then kept for $60 \mathrm{~min}$ in dark at room temperature, centrifuged for $5 \mathrm{~min}$ at 5,000 $\mathrm{g}$ and the absorbance was measured at $517 \mathrm{~nm}$ using a UV-Visible spectrophotometer (T70, UV/VIS spectrometer, PG Instruments Ltd., China). The control was conducted in the same manner, except that distilled water was used instead of sample. The DPPH radical scavenging activity was calculated as follows:

DPPH free radical-scavenging activity $(\%)=\left(\frac{A_{c}-A_{h}}{A_{c}}\right) \times 100$

where $A_{c}$ and $A_{h}$ are the absorbances of control and sample, respectively. A lower absorbance of the reaction mixture indicated a higher DPPH radical-scavenging activity. The test was carried out in triplicate.

\subsubsection{Reducing power assay}

The ability of AHE, gelatin gels and films to reduce iron (III) was determined according to the method of Yildirim et al. [20]. Films were cut into small pieces ( $\mathrm{m}=10 \mathrm{mg}$ ) and immersed in $0.1 \mathrm{ml}$ of distilled water. An aliquot of $0.1 \mathrm{ml}$ from AHE, dissolved film or gelatin gel was mixed with $2.5 \mathrm{ml}$ of $0.2 \mathrm{M}$ phosphate buffer (pH 6.6) and $2.5 \mathrm{ml}$ of $1 \%(\mathrm{w} / \mathrm{v}$ ) potassium ferricyanide. The mixtures were incubated for $30 \mathrm{~min}$ at $50{ }^{\circ} \mathrm{C}$. After incubation, $2.5 \mathrm{ml}$ of $10 \%(\mathrm{w} / \mathrm{v})$ trichloroacetic acid were added and the reaction mixtures were then centrifuged for $10 \mathrm{~min}$ at $10,000 \mathrm{~g}$. Finally, $2.5 \mathrm{ml}$ of the supernatant solution of each sample 
mixture were mixed with $2.5 \mathrm{ml}$ of distilled water and $0.5 \mathrm{ml}$ of $0.1 \%$ (w/v) ferric chloride. After a-10 min reaction time, the absorbance of the resulting solutions was measured at 700 nm. Higher absorbance of the reaction mixture indicated higher reducing power. The values are presented as the means of triplicate analyses.

\subsection{3. $\beta$-carotene-linoleate bleaching assay}

The ability of AHE, gelatin gels and films to prevent bleaching of $\beta$-carotene was determined. $0.5 \mathrm{mg} \beta$-carotene in $1 \mathrm{ml}$ chloroform was mixed with $25 \mu \mathrm{l}$ of linoleic acid and $200 \mu 1$ of Tween-40. The chloroform was completely evaporated under vacuum in a rotator evaporator at $40{ }^{\circ} \mathrm{C}$, then $100 \mathrm{ml}$ of double distilled water were added, and the resulting mixture was vigorously stirred. The emulsion obtained was freshly prepared before each experiment. Aliquots $(2.5 \mathrm{ml})$ of the $\beta$-carotene-linoleic acid emulsion were transferred to test tubes containing $0.1 \mathrm{ml}$ from each dissolved film or gelatin gel. The tubes were immediately placed in water bath and incubated at $50{ }^{\circ} \mathrm{C}$ for $2 \mathrm{~h}$. Thereafter, the absorbance of each sample was measured at $470 \mathrm{~nm}$. Control tube consisted of $0.5 \mathrm{ml}$ of distilled water instead of the sample solution. The antioxidant activity was evaluated in terms of bleaching of $\beta$-carotene using the following formula:

$$
\text { Inhibition (\%) }=\left(1-\frac{A_{0 s}-A_{120 s}}{A_{0 c}-A_{120 c}}\right) \times 100
$$

where $A_{0 s}$ and $A_{0 c}$ are the absorbances measured at zero time of incubation for the test sample and the control, respectively. $A_{120 s}$ and $A_{120 c}$ are the absorbances of the sample and the control, respectively, after incubation for $120 \mathrm{~min}$. Values are the mean of triplicate analyses.

\subsection{In vivo experimental study}

\subsubsection{Animals}

Healthy young Wistar rats weighing between 150 and 200 g were housed in individual clean polyethylene cages under controlled conditions (12 hours of light-dark cycle at 22-25 ${ }^{\circ} \mathrm{C}$ and $60-70 \%$ relative humidity) in the laboratory of the Faculty of Sciences of Sfax, 
Tunisia. Laboratory animal handling and experimental procedures were performed according the guidelines of the Tunisian Ethical Committee for the care and use of laboratory animals. During the experimental period (12 days), rats were maintained on standard pellet diet and allowed free access to tap water. A measure of animal's body weight has been realized every two days.

\subsubsection{Excision wound healing model}

After total anesthesia with ketamine (100 mg/kg body weight) by intramuscular injection, a circular area of approximately $150 \mathrm{~mm}^{2}$ wound was made on depilated thoracic region of rats. The wound day was considered as day 0 . The ointment was topically applied every two days till the complete epithelization, starting from the day of operation.

\subsubsection{Wound healing activity}

In this study, 48 rats were divided into 8 groups, containing each 6 animals.

Group 1 was untreated and served as the negative control (wounds were cleaned just with physiologic serum). Group 2 was treated with the reference drug «CICAFLORA» and served as a reference treated rats (positive control). Groups 3, 4, 5, 6, 7 and 8 were treated with F0, F1, F2, G0, G1 and G2, respectively.

After rinsing wounds with physiologic serum, the tested samples (films and hydrogels) and CICAFLORA were applied, in a fine layer covering the surface of the wound. The treatments were applied every two days till the wounds were completely healed. On day 12, all the rats were anaesthetized with ether, sacrificed and the granulation tissues were excised from the sacrificed animals.

\subsubsection{Blood and tissue collection}

Blood samples were collected from the sacrificed animals and placed immediately on ice for further analyses. Heparin was used as an anticoagulant blood. 
A part of wet wound tissue was preserved for histological examinations and the major part was preserved for biochemical analyses. So, they were firstly homogenized in TBS buffer (50 mM Tris-HCl; $150 \mathrm{mM} \mathrm{NaCl}$; $\mathrm{pH}$ 7.4), with a w/v ratio of (1:2), using an Ultra-Turax homogenizer. Then, the homogenates were centrifuged at 5,500 g for $15 \mathrm{~min}$ at $4{ }^{\circ} \mathrm{C}$ and the supernatants were collected and stored at $-80^{\circ} \mathrm{C}$ until use.

\subsection{Wound healing evaluation parameters}

\subsubsection{Chromatic study}

This study consists on attributing a chromatic code to the wound of each rat: bright red = blood covering the wound; dark red = coagulation of blood in the epidermis, red = granulation tissue; and pink = epithelialization step.

\subsubsection{Wound contraction and epithelialization time}

Throughout the experimental period, an excision wound margin was traced after wound creation by using transparent paper and each area was measured. Wound contraction was measured every 2 days, until complete wound healing and results were expressed in percentage of healed wound area. The percentage of wound closure was calculated using the following expression:

$$
\text { Wound closure }(\%)=\left(\mathrm{A}_{0}-\mathrm{A}_{\mathrm{d}}\right) / \mathrm{A}_{0} \times 100
$$

where $A_{0}$ and $A_{d}$ are the initial wound area (day 0 ) and the wound area on day (d), respectively. The period of epithelization was calculated as the number of days required for falling of the dead tissue without any residual raw wound.

\subsubsection{Hydroxyproline estimation}

Hydroxyproline content was estimated using the method of Lee and Tong [21]. Wound tissues were dried in a hot air oven at $60{ }^{\circ} \mathrm{C}$ to a constant weight and then hydrolyzed with $6 \mathrm{~N}$ $\mathrm{HCl}\left(1: 10\right.$, w:v) for $4 \mathrm{~h}$ at $130{ }^{\circ} \mathrm{C}$ in sealed glass tubes. The hydrolysates were neutralized to $\mathrm{pH} 7.0$ and then subjected to chloramine-T oxidation for $20 \mathrm{~min}$. The reactions were 
terminated by the addition of $0.4 \mathrm{M}$ perchloric acid and colors were then developed using Ehrlich reagent at $60{ }^{\circ} \mathrm{C}$ and measured at $557 \mathrm{~nm}$. Hydroxyproline concentrations were calculated from the linear standard curve and presented as mg/g of dry tissue weight.

\subsection{Quantitative protein determination}

Supernatants from tissue homogenates were used to measure total protein level according to the method of Lowry et al. [22] using bovine serum albumin (BSA) as standard.

\subsection{Evaluation of the antioxidant profile}

Supernatants from wound tissues homogenates were used to evaluate the activity of the antioxidant enzymes (CAT, SOD and GPx). CAT was measured according to the method of Aebi [23]. The reaction initiated by adding the $\mathrm{H}_{2} \mathrm{O}_{2}(500 \mathrm{mM})$ to the supernatant. The over time decomposition rate of $\mathrm{H}_{2} \mathrm{O}_{2}$ was measured at $240 \mathrm{~nm}$ to determine the catalase activity ( $\mu \mathrm{M} \mathrm{H} \mathrm{H}_{2} \mathrm{O}_{2}$ /mg protein in tissue). The SOD enzymatic activity is directly proportional to the inhibition rate of nitroblue tetrazolium (NBT) oxidation by $\mathrm{O}_{2}^{-}$anion. The absorbance was read at $580 \mathrm{~nm}$ and the specific activity was expressed as U/mg protein in tissue. A unit of enzyme was defined as the amount of enzyme that inhibits the oxidation reaction by $50 \%$. Glutathione peroxidase (GPx) activity was measured using the method described by Flohe and Gunzler [24]. The glutathione (GSH) oxidation by GPx is coupled to the transformation of 5,5-dithiobis-(2-nitrobenzoic)-acid (DTNB) into 2-nitro-5-thiobenzoate (TNB), which absorb at $412 \mathrm{~nm}$. Enzymatic activity was expressed as $\mu \mathrm{M} / \mathrm{g}$ protein in tissue.

\subsection{Lipid peroxidation assay}

Lipid peroxidation in supernatants from wound tissue homogenates was determined by estimating the malondialdehyde (MDA) level using thiobarbituric acid-reactive substances (TBARS) assay, referring to the method of Yagi [25]. The absorbance was measured at 530 $\mathrm{nm}$ and the results were expressed as the amount of MDA (nmol) per mg of protein. 


\subsection{Inflammatory markers}

Inflammatory states of rat groups were evaluated by measuring the C-reactive protein and plasma fibrinogen in blood samples, using high sensitivity enzyme Immunoassay kit11 and kit12, which were manufactured by MyBiosource, Inc. (San Diego, USA).

\subsection{Histological study}

Wound skin samples were fixed in a Bouin solution for $24 \mathrm{~h}$ for histological examination, and then transported in $10 \%$ neutral-buffered formalin. Tissues were then embedded in paraffin. Sections of $5 \mu \mathrm{m}$ in thickness were stained with hematoxylin and eosin (H\&E), and studied by a routine light microscope. The criteria that were studied in histopathological sections consisted on the re-epithelialization, cornification of the epithelium, fibroblast content, revascularizations and inflammatory cells presence.

\subsection{Statistical analysis}

Results were expressed as means \pm SEM (Standard Error Mean) and statistically analyzed using SPSS ver. 17.0, professional edition. A one-way analysis of variance (ANOVA) was then performed and followed by Duncun's test to estimate the significance among the main effects at the $5 \%$ probability level.

\section{Results and discussion}

\subsection{Analysis of volatile compounds}

The total phenolic content of aqueous henna extract (AHE) was determined according to the Folin-Ciocalteu method. The AHE contained about $580 \mathrm{mg}$ GAE/g of extract, which was higher than that reported by Hsouna et al. [26] (444 mg GAE/g of extract). In addition, a total 48 volatile components (aliphatic compounds, terpenoids, aromatics, sesquiterpenes, aldehydes, carboxylic acids, monoterpenes, etc.) were identified using GCMS. Those compounds are widely known, from the literature, to have antioxidant and other biological activities [27]. The major antioxidant volatile compounds in AHE are shown in Table 1. Data 
showed that AHE contained high amounts of lawsone (2-hydroxy-1,4-naphthalenedione), dimethyl sulfoxide, eugenol, dimethyl sulfide, and maltol, which were estimated as about $2.30 \%, 2.29 \%, 1.35 \% 1.22 \%$, and $0.63 \%$, respectively. It has been reported that lawsone, the major compound of henna, particularly concentrated in the leaf, displayed several biological properties such as antioxidant [6], antibacterial [28] and anti-inflammatory, analgesic, anticancer activities [7].

\subsection{In vitro antioxidant activity of AHE, CSG-gels and CSG-films incorporated with} AHE

The antioxidant activities of AHE, gelatin gels and films with or without AHE were monitored by DPPH radical scavenging activity, $\beta$-carotene-linoleate bleaching and reducing power assays (Table 2). First, AHE was found to exhibit antioxidant activities in a dose dependant manner, whatever the antioxidant assay used. The DPPH radical scavenging activity is based on the ability of antioxidant agents to donate a hydrogen atom or an electron to stabilize free radicals and to convert them to more stable product [29]. The radical scavenging activity of AHE at 50 and $500 \mu \mathrm{g} / \mathrm{ml}$ was about 55.8 and $88.7 \%$, respectively. The

presence of AHE extract with antioxidant activity can hinder the extent of $\beta$-carotene bleaching by neutralising the linoleate-free radicals formed in the emulsion system, and the activity reached 57 and $69 \%$ at 50 and $500 \mu \mathrm{g} / \mathrm{ml}$, respectively.

The observed activities could be due to the presence of phenolic compounds in the henna leaves. In fact, these compounds acted, in particular, as good proton donors reacting with free radicals to convert them to more stable products and terminate the radical chain reaction. Many researchers have shown the antioxidant activities of leaves henna extracts [6,30,31]. Mikaehil et al. [31] have indicated that henna leaves are rich in Lawsone, apigenin, luteolin, cosmosiin, p-coumaric acid, 2-methoxy-3-methyl-1,4-naphthoquinone and apiin, which are considered as excellent antioxidant compounds. 
On the other hand, CSG-gel and CSG-film without AHE were found to exhibit low antioxidant activities. The observed low antioxidant activity of control gelatin gel (G0) and film (F0) was probably related to the presence of some antioxidant peptides probably elaborated during gelatin extraction process $[15,16]$. Therefore, gelatin matrix alone could be used in dermal wound healing processes due to its bioactivity, biodegradable and biocompatible properties.

Interestingly, as expected, the incorporation of AHE in gelatin matrix improved significantly their antioxidant activities of the enriched gels and films. Further, the antioxidant activities were found to be dose dependant, which increased with the increase of AHE concentration in the gelatin matrix. In fact, the addition of AHE in cuttlefish gelatin based gel and film increased the radical scavenging activity. At $50 \mu \mathrm{g} / \mathrm{ml}, \mathrm{F} 1$ and G1 presented a radical scavenging ability two-fold higher $(\mathrm{p}<0.05)$ than that of F0 and G0, respectively. Interestingly, the radical scavenging effects of F2 and G2 enriched with $500 \mu \mathrm{g} / \mathrm{ml}$ of AHE reached 93 and $90.3 \%$, respectively.

Moreover, the antioxidant activities of gelatin matrix analyzed using the $\beta$-carotene bleaching assay showed that G2 and F2 displayed the highest ability to prevent the bleaching of $\beta$-carotene, with 80 and $81.5 \%$, respectively. Similarly, the ability to reduce ferric ion $\left(\mathrm{Fe}^{3+}\right)$ of film and gel enriched by AHE were higher than control film and gel $(\mathrm{p}<0.05)$, and the maximal findings were observed in G2 and F2 samples. These results proved that the antioxidant activity of AHE was not affected after its incorporation in the gelatin matrix (gel or film).

\subsection{Wound healing studies}

Gelatin is qualified as an excellent material for wound healing due to its biodegradable and biocompatible properties. Implanted gelatin will be degraded through native enzymatic pathways without any toxic response. Furthermore, the advantage provided by the films and 
gels of gelatin in the healing process is to maintain some moisture from the wound leading to promote healing process. In addition, through its permeability, gelatin matrix may limit the inflammatory response by exchanging water vapor between the wound and external environment. Further, gelatin may ensure a slow release of antioxidant and/or antimicrobial compounds incorporated within the matrix.

\subsubsection{Wound closure}

The percentage of contraction rates were monitored during the 12-days experimental period in order to assess the potential of CSG-films and CSG-gels enriched with henna extract at 50 and $500 \mu \mathrm{g} / \mathrm{ml}$ on wound healing. As reported in Table 3, the contraction rates of all treated groups were greater than that of the control group. Indeed, after 12 days, wound closure in control group attended only $80.88 \pm 1.67 \%$, while all treated groups showed a significant reduction in wound area was observed $(\mathrm{p}<0.05)$. After 4 days, a slight reduction in wound defect area for CICAFLORA (Group 2) and control (Group 1) animals was noted. These results were comparable to those of groups treated with gelatin film and gel without AHE. Interestingly, after the same period of application, rats treated with gels and films added with AHE showed faster healing rate (Table 3). The percent rates of wound contraction in groups 5 and 8 were about 53.07 and $49.47 \%$, respectively. Moreover, from the $2^{\text {nd }}$ day postwounding, initial inflammatory phase of the wound healing process, a decrease in the swelling in wounds treated with gelatin gels and films added with AHE was observed.

At the end of the experience, about the entire wound area has been contracted and the skin recovered its initial structure after the regular application of CICAFLORA, CSG gels and films incorporated with henna's extract. The best healing results were observed in AHE (500 $\mu \mathrm{g} / \mathrm{ml}$ ) gel and film treated groups, as shown in the wound closure percentages. Indeed, rats treated with F2 and G2 revealed $96.98 \%$ and $98.7 \%$ of contraction on the $12^{\text {th }}$ day, respectively. These results were comparable to the CICAFLORA treated group (96.56\%). In 
contrast, the control, gelatin film and gel without AHE treated animals showed an open wound, even at the end of the experience, with contraction rates estimated at $80.88,82.10$ and 86.88\%, respectively.

Therefore, it could be concluded that upon application of gelatin dressing enriched with $500 \mu \mathrm{g} / \mathrm{ml}$ of AHE, ointment induced a decrease in the epithelization period, along with a visibly increased wound closure, especially in gels-treated group. In fact, hydrogels are generally considered as a standard for wounds treatment, by producing high levels of exudates during the first step of wound healing process, and then hydrogels may help tissues to keep dried surface and to reduce the risk of infection [32]. The present study proved that gelatin gels added with henna extract exhibited a great wound healing effectiveness.

The slight difference noted between gels and films results in wound healing effectiveness, might be due to the fact that gelatin films partially prevent the passage of oxygen and water vapour. Thus, they can provide an effective barrier, but at the same time didn’t inhibit cutaneous respiration. This helps to avoid skin irriation in the area around the wound.

The wound size observations coupled with the closure percentages indicated that gelatin gels and films enriched with henna aqueous extract accelerated wound healing. Thus, they might be useful as a wound healing agent in tissue engineering. Our results are in accordance with those of Mandawgade and Patil [33] who demonstrated that ethanol henna leaf extract promoted wound healing by $97 \%$, compared to the control, in both excision and incision wound models in rats. In addition, a rapid wound contraction have been also observed in treated rats with ethanol Lawsonia ulba Lin leaf extract (71\%), compared to those treated with nitrofurazone ointment (70\%) and the untreated rats (58\%) [34].

Generally, flavonoids were associated with the wound-healing activity [35]. Lawsone was found to be more effective as wound-healing agent when applied externally in the form of 
an ointment [33]. In another study, Gopinath et al. [10] reported an improvement in the quality of wound healing by using a collagen film incorporated with curcumin.

\subsubsection{Hydroxyproline content in the wounds}

Collagen is the major component of extracellular tissue. Hydroxyproline, a major component of collagen, plays an important role in this protein stability. Therefore, hydroxyproline content is used as an indicator to determine collagen content.. Data reported in Table 4 demonstrate that hydroxyproline level in CSG-gels-AHE and CSG-films-AHE treated groups were significantly higher than control and CICAFLORA treated groups. However, the contents of hydroxyproline were similar whatever the concentration of AHE incorporated in the gelatin matrix. Notably, the application of G0 and F0 on wound improved slightly collagen synthesis.

The enhanced levels of hydroxyproline in gelatin gels and films containing AHE treated rats correlate very well with the stimulation of wound healing process. In fact, collagen is the component that ultimately contributes to wound strength [36]. It is mainly synthesized in the healing wound process. Furthermore, collagen is characterized by the presence of hydroxyproline and hydroxylysine formed by specific hydrolysis during the molecule assembly. Thus, a lack of hydroxyproline decreases the synthesis of collagen and the production of fibroblasts [37].

\subsubsection{Tissue antioxidant enzyme activities and MDA content}

The enzymatic activities of CAT, SOD and GPx as well as the MDA content, in wound tissues, were estimated (Table 4). Results indicated that untreated control rats possessed the lowest antioxidant enzymatic activities, while they showed the highest MDA tissue content ( $<<0.05)$, proving the presence of an oxidative stress state in these rats. However, the application of gelatin gels or films containing or not AHE enhanced significantly the 
antioxidant enzymatic activities and reduced the secondary oxidation products content (MDA).

It is interesting to note that the application of the CSG-film and CSG-gel gave a correction in terms of MDA content (0.38 and 0.39 nmole MDA/mg of protein), SOD (24.4 and 20.2 U/mg protein) and CAT (51.6 and $50.4 \mu \mathrm{M} \mathrm{H}_{2} \mathrm{O}_{2} / \mathrm{mg}$ protein) activities. Further, the CAT activity raised from $50.45 \mu \mathrm{M} \mathrm{H}_{2} \mathrm{O}_{2} / \mathrm{mg}$ protein to $53.80 \mu \mathrm{M} \mathrm{H}_{2} \mathrm{O}_{2} / \mathrm{mg}$ protein after the addition of $500 \mu \mathrm{g} / \mathrm{ml}$ of AHE in gelatin gel. Likewise, the SOD activity increased from 20.2 $\mathrm{U} / \mathrm{mg}$ of protein to $27.00 \mathrm{U} / \mathrm{mg}$ of protein after the incorporation of $500 \mu \mathrm{g} / \mathrm{ml}$ of AHE in gelatin gels. these enzyme activities were similar and eve higher than those obtained by CICAFLORA. This is may be due to the presence of peptides in the gelatin elaborated during the extraction process $[15,16]$. Similarly, Kim et al. [38] reported that antioxidant gelatin peptides may protect living cells against free radical mediated oxidative damage by enhancing cell viability against oxidation-induced cell death. These results are in accordance with the in vitro findings, which demonstrated that henna aqueous extract possessed potent antioxidant and free radical scavenging effects when incorporated in gelatin matrix. Therefore, it could be concluded that free radical species scavenging is an important mechanism, by which antioxidant compounds improve cell viability against oxidation-induced cell death. In addition, as previously demonstrated by Hsouna et al. [26], some of the constituents of henna could act as free radical scavengers, preventing phospholipid membrane from peroxidation and protecting immuno-compromised cells from free radical damage.

\subsubsection{Inflammatory markers evaluation}

C-reactive protein (CRP) and fibrinogen are the most used proteins in inflammatory status diagnostic. Their elevated levels predicted inflammation states. These two parameters were measured in the plasma of sacrificed animals at the end of the experience (Table 5). Fibrinogen is a multifunctional circulating glycoprotein involved in wound healing. 
Compared to the treated groups, the fibrinogen and CRP contents were significantly higher in untreated rats as compared to gelatin treated rats, which reflects the presence of inflammation in wound tissue. No significant difference was revealed between all treated groups in terms of fibrinogen content $(\mathrm{p}>0.05)$. Even the values given by the F0 and G0-treated groups were less effective compared to the other treatments; they were significantly inferior to the control rats and similar to rats treated with CICAFLORA.

The acceleration rate of wound contraction induced by gelatin matrix incorporated with AHE may be due to stimulation of interleukin- 8 , an inflammatory $\alpha$-chemokine, which affects the function and recruitment of various inflammatory cells, fibroblasts and keratinocytes, and inducing faster maturation of granulation tissue [39]. Gupta et al. [40] demonstrated that leaves henna extract showed significant anti-inflammatory effect with some active principles in a dose dependant manner. Furthermore, aqueous leaf extract was found to reduce inflammation in carrageenan-induced hind paw oedema in rats at a dose of $250 \mathrm{mg} / \mathrm{kg}$ [40].

In this context, it has been reported that henna (L. inermis L.) leaf extract at a dose of $200 \mathrm{mg} / \mathrm{kg}$ [33] and $500 \mathrm{mg} / \mathrm{kg}$ [41] promoted wound healing in model rats in comparison to the positive control, phenylbutazone (100 mg/kg) [41]. Further, Lawsone from the henna leaf extract was found to promote healing of both excision and incision wounds in rats, when administered orally, or when applied externally in the form of an ointment [33]. Moreover, reports of the European Commission, formulated by the Scientific Committees on Consumer Products (SCCSP) and Consumer Safety (SCCS) [42,43] provide a summary of detailed toxicity studies done on henna, as required for product registration. An acute toxicity study of henna conducted in Sprague-Dawley rats established the median oral lethal dose as above $2000 \mathrm{mg} / \mathrm{kg}$ of body weight, while an acute dermal toxicity assay in Wistar rats also yielded a median lethal dose of more than $2000 \mathrm{mg} / \mathrm{kg}$ of body weight [42,43]. In addition, henna did not display signs of irritation potential when tested for acute dermal toxicity [29]. In our 
study, the dose of henna used was $500 \mu \mathrm{g}$ per milliliter of gelatin gel, which did not exceed the superior limit required by the SCCP [42]. Therefore, it could be applied on human skin as natural, safe and efficient ointment for wound healing.

Overall, based on antioxidant and inflammatory markers, our results revealed that AHE incorporated in gelatin gels or films possessed potent antioxidant activities, which help to prevent tissues against inflammation and oxidative damage, resulting in healing process promoting.

\subsubsection{Histological study}

In the present study, hematoxylin and eosin stained sections of wound tissues were used to evaluate re-epithelization, collagen content, revascularization, and organization of collagen, fibroblasts and inflammatory cells. The micrograph sections of the different wound tissues are presented in Fig. 1.

The histological study of the granulation tissue of untreated group showed that the wound still not fully restored and the wound re-epithelization was incomplete. Numerous inflammatory cells including lymphocytes, plasma cells and macrophages infiltrated the dermis. Furthermore, the newly formed collagen was still unorganized (Fig. 1B). The form of the tissues of the gel treated groups (Fig. 1G, H and I) was different from those treated by films (Fig. 1C, D and E) and showed better wound re-epithelization. Hermans and Bolton [32] reported that hydrogels application limit the inflammatory response by exchanging water vapor between the wound and the external environment.

Interestingly, wound tissue sections of the rats treated with gel added with $500 \mu \mathrm{g} / \mathrm{ml}$ of AHE was regarded as a modified tissue formation that enhances wound re-epithelialization. In fact, inflammatory cells disappeared, neo-vascularisation and connective tissue was densely formed in the group treated with CSG gel incorporated by $500 \mu \mathrm{g} / \mathrm{ml}$ of AHE (Fig. 1I). The fibroblasts are responsible for synthesis, deposition, and remodeling of the extracellular 
matrix. After migrating into wounds, fibroblasts initiate the synthesis of the extracellular matrix. These results suggest that the biocompatibility of the gelatin gels incorporated with AHE might stimulate the surrounding healthy cells in the wound site to generate the growth factors required for wound healing.

Compared to those of the untreated lesions (Fig. 1B), a lower number of lymphocytes, macrophages and inflammatory cells have infiltrated the dermis and fibroblasts were more organized, and the tissue was aligning [44].

\section{Conclusion}

In summary, results obtained in this study provide evidence that hydrogels or films based on cuttlefish skin gelatin incorporated with aqueous extract of henna (L. inermis), besides their in vitro antioxidant effects, they found to enhance significantly the healing process. In addition, gelatin gels and films may help to prevent from inflammation and oxidative damage. These characteristics suggest the beneficial role of ointment, based on CSG/AHE, on improving the rebalance between the chronic wound environment and therefore promoting healing. Therefore, gelatin gel and film could be used as matrix carrier for antioxidant and antimicrobial bioactive substances to promote healing process.

\section{Acknowledgements}

This work was funded by the Ministry of Higher Education and Scientific Research, Tunisia. This work was funded by the Ministry of Higher Education and Scientific Research, Tunisia. Emerging Research Group Grant from Generalitat Valenciana in Spain (GV/2015/138) and JAEDOC-CSIC postdoctoral contract of L.M. cofounded by the European Social Found are acknowledged.

\section{References}


[1] I. Syamsudin, H. Winarno, The effect of Inai (L. inermis Linn) leaves extract on blood sugar level: An experimental study, Res. J. pharmacol. 2 (2008) 20-23.

[2] M.S. Arayne, N. Sulthana, A.Z. Mirza, M.H. Zubri, F.A. Siddiqqui, In vitro hypoglycemic activity of methanolic extract of some indigenous plants, Pak. J. pharm. Sci. 20 (2007) 268-273.

[3] V.K.P. Subbaiah, N. Savithrmma, Bio-prospecting and documentation of traditional plants used to treat itching, psoriasis and wounds by ethnic groups of Kurnool district, Andhra Pradesh, India, Asian. J. Pharm. Clin. Research. 5 (2012) 127-131.

[4] Z.S. Khan, S. Nasreen, Antibacterial activity of some medicinal plants, J. Pure. Appl. Microbio. 4 (2010) 393-396.

[5] T. Dasgupta, A.R. Rao, P.K. Yadava, Modulatory effect of Henna leaf (Lawsonia inermis) on drug metabolising phase I and phase II enzymes, antioxidant enzymes, lipid peroxidation and chemically induced skin and forestomach papillomagenesis in mice, Mol. Cell. Biochem. 245 (2003) 11-22.

[6] A. Adetutu, O.A. Owoade, O.S. Oyekunle, Comparative effects of some medicinal plants on sodium arsenite-induced clastogenicity, Int. J. Pharm. Bio. Sci. 4 (2013) 777-783.

[7] H. Imam, N.U. Mahbub, M.F. Khan, H.K. Hana, M.M. Sarker, Alpha amylase enzyme inhibitory and anti-inflammatory effect of Lawsonia inermis, Pak. J. Biol. Sci. 16 (2013) 1796-1800.

[8] S.P. Pattanayak, P. Sunita, Wound healing, anti-microbial and antioxidant potential of Dendrophthoe falcata (L.f) Ettingsh, J. Ethnopharmacol. 120 (2008) 241-247.

[9] K. Robards, P.D. Prenzler, G. Tucker, P. Swatsitang, W. Glover, Phenolic compounds and their role in oxidative processes in fruits, Food. Chem. 66 (1999) 401-436.

[10] D. Gopinath, M.R. Ahmed, K. Gomathi, K. Chitra, P.K. Sehgal, R. Jayakumar, Dermal wound healing processes with curcumin incorporated collagen films, Biomaterials. 25 (2004) 1911-1917.

[11] H. Wiseman, B. Halliwell, Damage to DNA by reactive oxygen and nitrogen species: role in inflammatory disease and progression to cancer, Biochem. J. 313 (1996) 17-29.

[12] A. Wang, Y. Cui, J. Li, J.C.M. van Hest, Fabrication of Gelatin Microgels by a "Cast” Strategy for Controlled Drug Release, Adv. Funct. Mater. 22 (2012), 2673-2681.

[13] A. Wang, Y. Yang, X. Zhang, X. Liu, W. Cui, J. Li, Gelatin-assisted synthesis of vaterite nanoparticles with higher surface area and porosity as anticancer drug containers in vitro, ChemPlusChem. 81 (2016) 194-201. 
[14] M. Fu, A. Wang, X. Zhang, L. Dai, J. Li, Direct observation of the distribution of gelatin in calcium carbonate crystals by super-resolution fluorescence microscopy, Angew. Chem. Int. Ed. 55 (2016) 908-911.

[15] M. Jridi, N. Souissi, A. Mbarek, G. Chadeyron, M. Kammoun, M. Nasri, Comparative study of physico-mechanical and antioxidant properties of edible gelatin films from the skin of cuttlefish, Int. J. Biol. Macromol. 61 (2013) 17-25.

[16] M. Jridi, R. Nasri, I. Lassoued, N. Souissi, A. Mbarek, A. Barkia, M. Nasri, Chemical and biophysical properties of gelatins extracted from alkali-pretreated skin of cuttlefish (Sepia officinalis) using pepsin, Food. Res. Int. 54 (2013) 1680-1687.

[17] A. Martin, The use of antioxidants in healing, Dermatol. Surg. 22 (1996) 156-160.

[18] G.C. Mittal, C.N. Aguwa, Abortifacient effects of the root of Mormodica angustisepala, J. Ethnopharmacol. 7 (1983) 169-173.

[19] P. Bersuder, M. Hole, G. Smith, Antioxidants from a heated histidine-glucose model system. I: Investigation of the antioxidant role of histidine and isolation of antioxidants by high performance liquid chromatography, J. Am. Oil Chem. Soc. 75 (1998) 181-187.

[20] A. Yildirim, A. Mavi, A.A. Kara, Determination of antioxidant and antimicrobial activities of Rumex crispus L. extracts, J. Agric. Food Chem. 49 (2001) 4083-4089.

[21] K.H. Lee, T.G. Tong, Studies on the mechanism of action of salycylates. II. Retardation of wound healing by aspirin, J. Pharm. Sci. 57 (1968) 1042-1043.

[22] O.H. Lowry, N.J. Rosebrough, A.L. Farr, R.J. Randall, Protein measurement with the Folin phenol reagent, J. Biol. Chem. 193 (1951) 265-275.

[23] H. Aebi, Catalase in vitro, Methods Enzymol. 105 (1984) 121-126.

[24] L. Flohé, W.A. Günzler, Assay of glutathion peroxydase, Methods Enzymol. 105 (1984) 114-121.

[25] K. Yagi, A simple fluorometric assay for lipoperoxide in blood plasma, Biochem. Med. 15 (1976) 212-216.

[26] A.B. Hsouna, M. Trigui, G. Culioli, Y. Blache, S. Jaoua, Antioxidant constituents from Lawsonia inermis leaves: isolation, structure elucidation and antioxidative capacity, Food Chem. 125 (2011) 193-200.

[27] T. Mengoni, D.V. Peregrina, R. Censi, M. Cortese, M. Ricciutelli, F. Maggi, P. Di Martino, SPME-GC-MS analysis of commercial henna samples (Lawsonia inermis L.), Nat. Prod. Res. (2016) 268-275. 
[28] J.Y. Yang, H.S. Lee, Antimicrobial activities of active component isolated from Lawsonia inermis leaves and structure-activity relationships of its analogues against foodborne bacteria, J. Food Sci Technol. 52 (2015) 2446-2451.

[29] W. Binsan, S. Benjakul, W. Visessanguan, S. Roytrakul, M. Tanaka, H. Kishimura, Antioxidative activity of Mungoong, an extract paste, from the cephalothorax of white shrimp (Litopenaeus vannamei), Food Chem. 106 (2008) 185-193.

[30] R.B. Semwal, D.K. Semwal, S. Combrinck, C. Cartwright-Jones, A. Viljoen, Lawsonia inermis L. (henna): Ethnobotanical, phytochemical and pharmacological aspects, Journal of Ethnopharmacology 155 (2014) 80-103.

[31] B.R. Mikaehil, F.A. Badria, G.T. Maatooq M.M.A. Amer, Antioxidant and immunomodulatory constituents of henna leaves, Z. Naturforsch. 59 (2004) 468- 476.

[32] M.H.E. Hermans, L.L. Bolton, Establishing a skin integrity program, Remington Report, 1 (2001) 6-8.

[33] S.D. Mandawgade, K.S. Patil, Wound healing potential of some active principles of Lawsonia alba Lam. leaves, Indian. J. Pharm. Sci. 65 (2003) 390-394.

[34] V. Nithya, A. Baskar, A Preclinical study on wound healing activity of Lawsonia ulba Linn, Res. J. Phytochem. 5 (2011) 123-129.

[35] D.K. Semwal, U. Rawat, A. Bamola, R. Semwal, Antimicrobial activity of Phoebe lanceolata and Stephania glabra; preliminary screening studies, J. Sci. Res. 1 (2009) 662-666.

[36] J. Li, J. Chen, R. Kirsner, Pathophysiology of acute wound healing, Clin. Dermatol. 25 (2007) 9-18.

[37] C.L. Harris, C. Fraser, Malnutrition in the institutionalized elderly: the effects on wound healing, Ostomy Wound Manage. 50 (2004) 54-63.

[38] S.K. Kim, E. Mendis, Bioactive compounds from marine processing byproducts: A review, Food Res. Int. 39 (2006) 383-93.

[39] M. Singh, P. Chand, M.K. Rai, Screening of anticariogenic activity of some Indian medicinal plants. J. Ecophysiol. Occup. Health 8 (2008) 177-181.

[40] B.N. Gupta, A.K. Mathur, C. Agarwal, A. Singh, Contact sensitivity to henna, Contact Dermatitis. 15 (1986) 303-304.

[41] G. Chaudhary, S. Goyal, P. Poonia, Lawsonia inermis Linnaeus: A Phytopharmacological Review, Int. J. Pharm. Sci. Drug. Res. 2 (2010) 91-98.

[42] Scientific Committee on Consumer Products (SCCP), Opinion on tagetes erecta, T. minuta and T. patula extracts and oils (phototoxicity only), adopted by the SCCP during the 4th plenary of 21 June (2005). 
[43] S.C.C.S, P.J. Coenraads. Opinion of the Scientific Committee on Consumer Safety (SCCS)-Opinion on the fragrance ingredients Tagetes minutaand Tagetes patula extracts and essential oils (phototoxicity only) in cosmetic products, Regul. Toxicol Pharmacol. 76 (2013) 213-214.

[44] B.S. Nayak, G. Isitor, E.M. Davis, G.K. Pillai, The evidence based wound healing activity of Lawsonia inermis Linn, Phytother. Res. 21 (2007) 827-831. 
Table 1: Identification of major volatile compounds in AHE.

\begin{tabular}{cccccc}
\hline Compound & Retention time & Area \% & LRI $^{\mathbf{a}}$ compound & LRI $^{\mathbf{a}}$ standard & Mw \\
\hline Dimethyl sulfide & 4.26 & 1.22 & 533 & 532 & 94.2 \\
Hexenal & 8.36 & 0.53 & 642 & 643 & 100.1 \\
Dimethyl sulfoxide & 17.66 & 2.29 & 941 & 939 & 78.1 \\
Phenol & 25.47 & 0.35 & 1105 & 1104 & 94.1 \\
Maltol & 36.10 & 0.63 & 1192 & 1192 & 126.1 \\
Eugenol & 46.62 & 1.35 & 1432 & 1433 & 164.2 \\
Lawsone & 58.96 & 2.30 & 1659 & 1660 & 174.1 \\
\hline
\end{tabular}

${ }^{a}$ Linear retention index (LRI) of the compounds eluted from the GC-MS using a DB-624 column capillary column. Mw: Molecular Weight 
Table 2: Radical scavenging, $\beta$-carotene bleaching inhibition and reducing power activities of AHE, gelatin gels and films enriched with AHE at different concentrations.

\begin{tabular}{|c|c|c|c|c|}
\hline & & $\begin{array}{c}\text { DPPH } \\
\text { scavenging (\%) }\end{array}$ & $\begin{array}{l}\beta \text {-carotene bleaching } \\
\text { inhibition }(\%)\end{array}$ & $\begin{array}{c}\text { Reducing power } \\
\text { (OD } 700)\end{array}$ \\
\hline \multirow{2}{*}{ AHE } & $50 \mu \mathrm{g} / \mathrm{ml}$ & $55.78 \pm 2.10$ & $56.8 \pm 0.37$ & $0.42 \pm 0.02$ \\
\hline & $500 \mu \mathrm{g} / \mathrm{ml}$ & $88.68 \pm 0.16$ & $69.2 \pm 1.36$ & $1.13 \pm 0.07$ \\
\hline \multirow{3}{*}{ Film } & F0 & $30.99 \pm 0.71^{\mathrm{d}}$ & $10.65 \pm 0.15^{\mathrm{d}}$ & $0.215 \pm 0.07^{\mathrm{e}}$ \\
\hline & F1 & $61.86 \pm 1.15^{\mathrm{c}}$ & $60.51 \pm 1.36^{b}$ & $0.59 \pm 0.05^{d}$ \\
\hline & F2 & $92.99 \pm 0.71^{a}$ & $81.25 \pm 0.97^{\mathrm{a}}$ & $1.65 \pm 0.02^{\mathrm{a}}$ \\
\hline \multirow{3}{*}{ Gel } & G0 & $29.63 \pm 3.88^{d}$ & $23.69 \pm 2.69^{c}$ & $0.203 \pm 0.05^{\mathrm{e}}$ \\
\hline & G1 & $61.99 \pm 1.63^{c}$ & $80.54 \pm 0.26^{\mathrm{a}}$ & $0.866 \pm 0.03^{\mathrm{c}}$ \\
\hline & G2 & $90.31 \pm 0.81^{b}$ & $80.02 \pm 1.69^{a}$ & $0.944 \pm 0.01^{b}$ \\
\hline
\end{tabular}


Table 3: Effect of different treatments on wound closure

\begin{tabular}{|c|c|c|c|c|c|c|c|}
\hline \multirow{2}{*}{ Group } & \multicolumn{7}{|c|}{ Days } \\
\hline & $\mathbf{0}$ & 2 & 4 & 6 & 8 & 10 & 12 \\
\hline Group 1 & 0.00 & $10.33 \pm 0.15^{d}$ & $21.63 \pm 0.82^{\mathrm{e}}$ & $45.02 \pm 1.56^{c}$ & $57.55 \pm 2.59^{\mathrm{f}}$ & $70.56 \pm 1.31^{\mathrm{e}}$ & $80.88 \pm 1.67^{f}$ \\
\hline Group 2 & 0.00 & $16.33 \pm 1.26^{\mathrm{bc}}$ & $29.50 \pm 3.6^{\mathrm{d}}$ & $36.81 \pm 2.13^{d}$ & $69.74 \pm 1.75^{\mathrm{d}}$ & $92.11 \pm 1.48^{\mathrm{a}}$ & $96.56 \pm 0.64^{b}$ \\
\hline Group 3 & 0.00 & $15.12 \pm 0.86^{\mathrm{a}}$ & $32.82 \pm 0.51^{d}$ & $54.46 \pm 1.93^{b}$ & $71.25 \pm 2.62^{d}$ & $78.62 \pm 1.68^{d}$ & $82.10 \pm 0.36^{f}$ \\
\hline Group 4 & 0.00 & $19.62 \pm 1.69^{b}$ & $48.75 \pm 1.32^{b}$ & $58.47 \pm 2.49^{\mathrm{a}}$ & $73.12 \pm 1.39^{c}$ & $90.36 \pm 0.28^{\mathrm{a}}$ & $92.15 \pm 0.62^{d}$ \\
\hline Group 5 & 0.00 & $26.97 \pm 2.95^{\mathrm{a}}$ & $53.07 \pm 0.62^{\mathrm{a}}$ & $57.60 \pm 2.91^{\mathrm{a}}$ & $76.90 \pm 1.28^{\mathrm{b}}$ & $90.30 \pm 0.16^{\mathrm{a}}$ & $96.98 \pm 0.29^{b}$ \\
\hline Group 6 & 0.00 & $6.49 \pm 4.91^{\mathrm{e}}$ & $26.99 \pm 2.62^{a}$ & $44.86 \pm 1.53^{c}$ & $64.81 \pm 0.79^{\mathrm{e}}$ & $84.69 \pm 0.97^{b}$ & $86.88 \pm 0.48^{\mathrm{e}}$ \\
\hline Group 7 & 0.00 & $18.34 \pm 1.12^{b}$ & $35.41 \pm 2.86^{c}$ & $40.52 \pm 2.10^{\mathrm{cd}}$ & $65.05 \pm 1.11^{\mathrm{e}}$ & $81.86 \pm 0.16^{c}$ & $94.68 \pm 0.23^{c}$ \\
\hline Group 8 & 0.00 & $22.20 \pm 2.50^{\mathrm{ab}}$ & $49.47 \pm 1.56^{b}$ & $62.73 \pm 3.62^{\mathrm{a}}$ & $80.41 \pm 0.98^{a}$ & $90.69 \pm 0.89^{a}$ & $98.70 \pm 0.12^{\mathrm{a}}$ \\
\hline
\end{tabular}


Table 4: Effect of different treatments on antioxidant states of rat groups

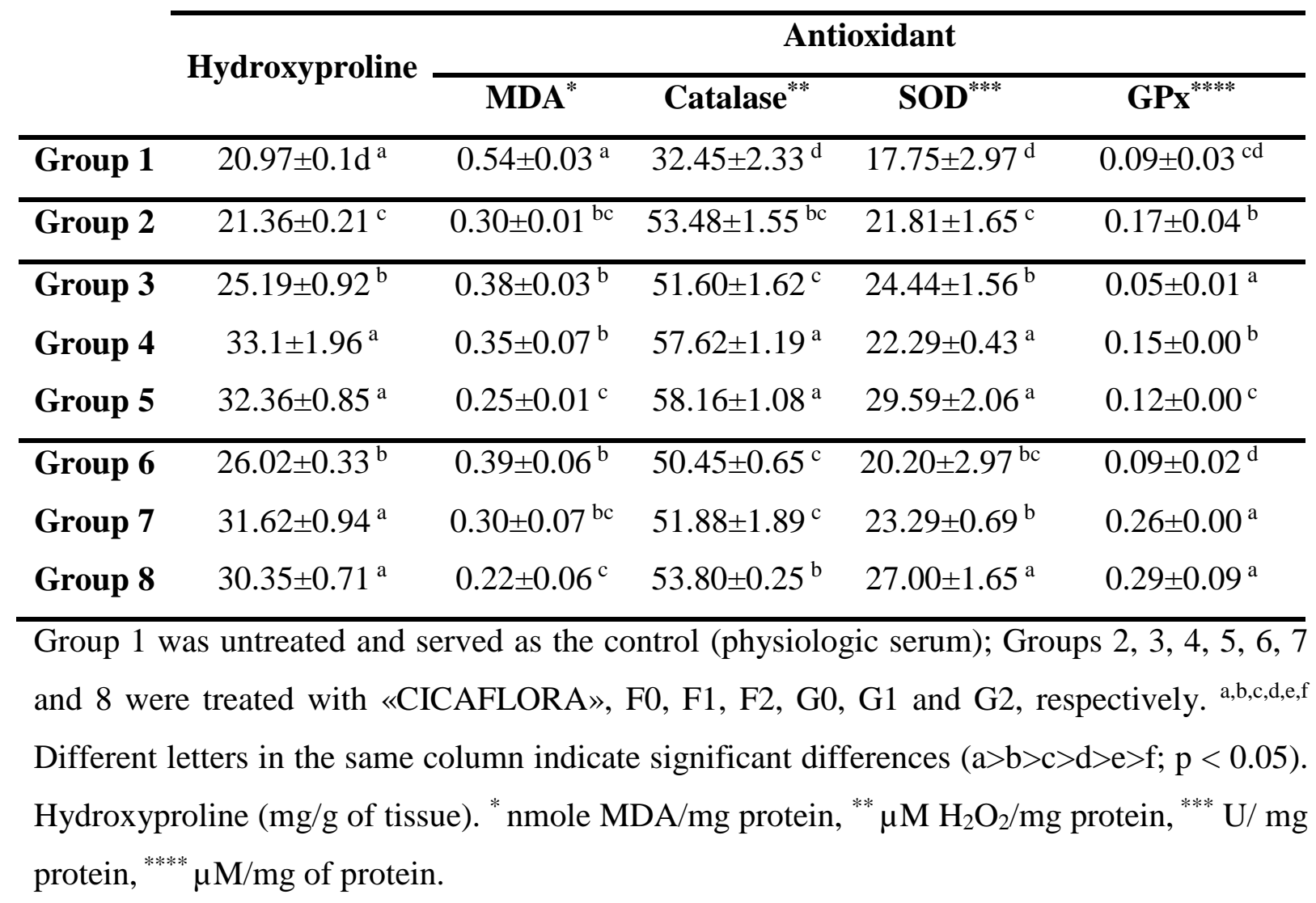


Table 5: Plasma fibrinogen and C-reactive protein levels

\begin{tabular}{ccc} 
& Fibrinogen $(\mathbf{g} / \mathbf{l})$ & CRP $(\mathbf{m g} / \mathbf{l})$ \\
\hline Group 1 & $4.88 \pm 0.95^{\mathrm{a}}$ & $2.53 \pm 0.26^{\mathrm{a}}$ \\
\hline Group 2 & $2.31 \pm 0.32^{\mathrm{b}}$ & $1.86 \pm 0.01^{\mathrm{b}}$ \\
\hline Group 3 & $2.62 \pm 0.33^{\mathrm{b}}$ & $1.98 \pm 0.16^{\mathrm{b}}$ \\
Group 4 & $2.41 \pm 0.4^{\mathrm{b}}$ & $1.65 \pm 0.15^{\mathrm{c}}$ \\
Group 5 & $2.06 \pm 0.35^{\mathrm{b}}$ & $1.48 \pm 0.12^{\mathrm{bc}}$ \\
\hline Group 6 & $2.26 \pm 0.13^{\mathrm{b}}$ & $1.98 \pm 0.15^{\mathrm{b}}$ \\
Group 7 & $2.08 \pm 0.19^{\mathrm{c}}$ & $1.44 \pm 0.36^{\mathrm{bc}}$ \\
Group 8 & $2.68 \pm 0.09^{\mathrm{b}}$ & $1.59 \pm 0.41^{\mathrm{bc}}$ \\
\hline
\end{tabular}

Group 1 was untreated and served as the control (physiologic serum); Groups 2, 3, 4, 5, 6, 7 and 8 were treated with «CICAFLORA», F0, F1, F2, G0, G1 and G2, respectively. a,b,c Different letters in the same column indicate significant differences $(a>b>c ; p<0.05)$. 
Fig. 1. The representative photomicrographs of wounds architecture on the 12th day. HEstained histological sections are $5 \mathrm{~mm}$ thick and photomicrographs are taken at magnification 100 x. Group 1 was untreated and served as the control (physiologic serum) (B); Groups 2c, 3d, 4e, 5f, 6g, 7h and 8i were treated with «CICAFLORA», F0, F1, F2, G0, G1 and G2, respectively. 
Fig. 1
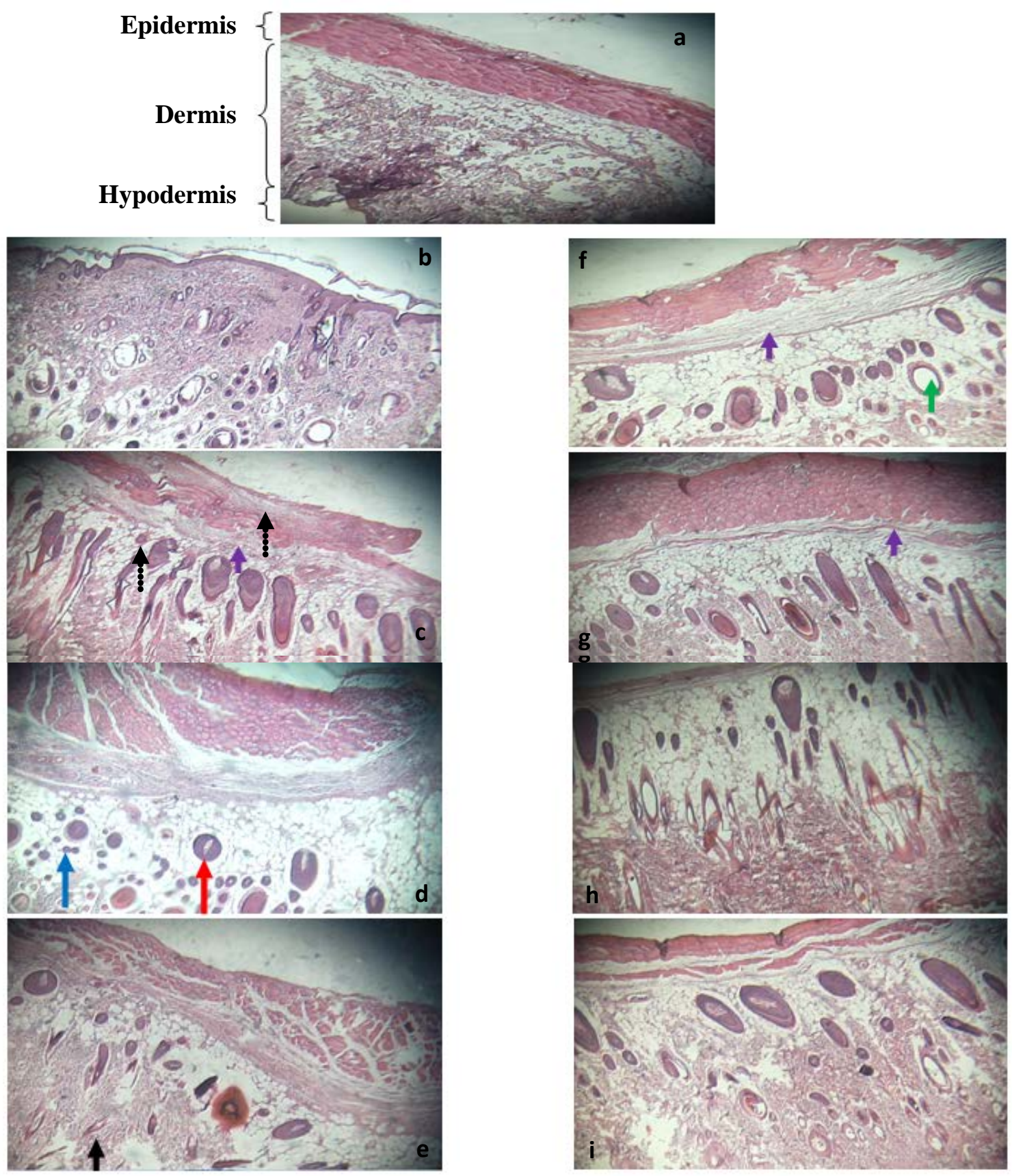

White blood cell; $\mathbf{\uparrow}$ Fibroblast; $\uparrow$ Dilated blood vessel, $\uparrow$ Dermal membrane; $\uparrow$ Blood vessel and inflammatory cell. 